\section{Early Man in South Africa}

I would be glad to be allowed to point out that Dr. Leakey's results in Kenya are very closely similar to those found by me on the south coast of Africa - the quartzite area-except in the matter of time.

Leakey's Kanjera skulls are, as stated by Sir Arthur Keith, definitely negroid; in fact to judge merely by his fragments, very closely similar indeed to the man responsible for the Early Mossel Bay industry - of whom I now have three adult (one described by Keith ${ }^{1}$ ) and one juvenile skulls, that described by Keith, with its boat-shaped frontal region, being very aberrant in this respect. This Early Mossel Bay (without a doubt much earlier than the Still Bay and its associated Fish Hock skull) is found in natural strata in the Grey Zone at the base of the Superficial Black layer ${ }^{2}$ (also recently found much more numerously in the same zone at Plettenberg Bay by me), and this Black layer, representing present climatic conditions, must be taken to be Holocene.

This prehistoric South African (or Kanjera man), however, was not only Holocene. In 1934-35 I found sufficient fragments of a Late Stellenbosch skull in a shelter at Plettenberg Bay to convince anyone seeing them that they represent the very same type of man. These Late Stellenbosch implements are extremely common in the Red Sand below the Black layer (see also ref. 2), that is, in a deposit representing an arid period before the Holocene.

If we now assume that the Middle Stellenbosch, at least, is due to the same human race, we at last come to the prehistoric South African more or less eontemporaneous with Leakey's Kanjera man. Here then we have perfect harmony between South and East Africa, except that Leakey, dealing with massive deposits from large volumes of water, may perhaps be overestimating the age of these deposits.

If we now proceed to the lydianite area of the Free State, we find other resemblances-again excepting in the matter of time. A beautifully preserved series of deposits of a streamlet, each carrying implements, is to be seen at Bayswater, Bloemfontein. At a single spot, the following succession is preserved, the whole being more than twenty feet in thickness :--

(1) Gravelly blue clay, blue clay, unconformity, representing a period of erosion (drought) during which the recently laid down strata were eroded away.

(2) Red boulder gravel, red grit, red clay, calcareous clay (only preserved towards the downstream end), black clay (only a small piece preserved at the extreme downstream end of the exposure), unconformity.

(3) Red boulder gravel, red grit, red clay, unconformity (at this spot the expected calcareous clay and black clay were completely eroded away).

(4) Reddish sand with its top heavily impregnated with lime-uneonformity.

(5) Black layer. At this exposure the Layer 3 forms a little hillock so that the Layer 5 has been mostly eroded away.

To my mind, this series can only mean one thingthat the strata represent the remains of five climatic cyeles - the same number represented by the sand and peat layers twenty-four miles away at Floris Bad; and from Layer 1 to Layer 4 the lydianite culture was evolving in the same way as is to be seen at the Floris Bad and other sites. It, like the quartzite Stellenbosch, commences as a Clacton-like phase, with large Stellenbosch-like implements in dolerite; but the use of dolerite is almost at once abandoned (except for the production of large horse-hoof shaped cleavers-which are found through all the phases of the culture) and the Iydianite flakes pass through Mousterian-like, Aurignacian-like and Magdalenianlike phases, all the phases continuing to be associated with extinct species of mammals. The curious point about this evolution of the lydianite culture is that all its phases, especially the earlier ones, remind one (and Mr. Van Riet Lowe agrees with me here) of Leakey's Early Kenyan Aurignacian.

The early history of South Africa is not therefore as Leakey describes it for Kenya (with a MousterianAurignacian technique following on a ChelleanAcheulean); not as it has been expressed in the accepted classification of South African stone implements ; not as it used to be described for Europebut as Breuil now accepts it for Europe, namely, with a contemporaneous evolution of the ChelleanAcheulean and a Clacton-Mousterian technique. The only difference is that, in Europe, one can see no reason for this difference, whereas in South Africa the difference in the available material would to some extent explain it.

It is not only in the stratification of natural deposits, and in the mammalian fossils of these, that the extreme age of the lydianite Clacton-Mousterian, as compared with the Late Stellenbosch, is to be seen; but also in the nature of the human remains. The latter is associated with Kanjera man (better prehistoric South Africans), the former with the huge, very primitive ancestral form of $H$. sapiens ${ }^{3}$, which, it may be said in passing, has no points of resemblance, except in size, with the extremely dubious Rhodesian man.

\section{Grey University College, Bloemfontein.} Feb. 25.

${ }^{1}$ Roy. Soc. S. Africa, 21, Pt. ii.

s "Floris Bad Man", Dreyer and Ariens Kappers, Kon. Akad. Amsterdam, 1935.

\section{Distribution of Nuclear Mechanical Moments}

AT present, the nuclear mechanical spins of about fifty atoms, including about sixty isotopes, are known. Of these, the spins of fifty-three odd atomic weight isotopes are known with a fair degree of certainty, some doubt existing only in very few cases. Two types of odd atomic weight atoms exist, namely, those with odd atomic number $(A)$ and those with even atomic number $(B)$. The former possess an odd nuclear proton, the latter an odd nuclear neutron. Amongst the fifty-three fairly reliable spins, thirty-nine belong to the former class and fourteen to the latter. The distributions of the nuclear mechanical moments in the two classes are shown in Fig. 1.

The difference in the distributions is very striking. No significance is probably to be attached to the missing $\frac{5}{2}$ spin atoms in the lower curve, for as yet only a little more than half of all the atoms of the Periodic Table have been studied. In spite of this, the above distributions appear to have real significance. Thus although class $B$ atoms are only onethird as numerous as class $A$, yet there are more spins of $\frac{1}{2}$ in class $B$ than in class $A$, and this can scarcely be accidental in view of the general trends of both the curves. 